\title{
Atribuição de estados mentais e compreensão conversacional: estudo com pré-escolares $^{1}$
}

\author{
Maria Regina Maluf ${ }^{2}$ \\ Eliana Cristina Gallo-Penna \\ Pontifícia Universidade Católica de São Paulo, São Paulo-SP, Brasil \\ Maria José dos Santos \\ Universidade Federal de Goiás, Goiânia-GO, Brasil
}

\begin{abstract}
Resumo: A habilidade de atribuir a si próprio e ao outro estados mentais como desejos, intenções e crenças é denominada teoria da mente. Pesquisas recentes mostram relações entre aspectos da linguagem e aquisição de uma teoria da mente. Este estudo investiga as relações entre compreensão conversacional, entendida como um aspecto da pragmática da linguagem, e a atribuição de estados mentais. Participaram da pesquisa 28 crianças de quatro a seis anos, de ambos os sexos, de nível socioeconômico baixo, distribuídas em dois grupos de idade. A coleta de dados foi feita por meio da aplicação individual de tarefas de compreensão conversacional e de teoria da mente. Os resultados mostraram efeito da idade a favor das crianças mais velhas, para as duas variáveis, bem como uma correlação positiva entre elas, o que está de acordo com achados de pesquisas anteriores.
\end{abstract}

Palavras-chave: teoria da mente, pré-escolares, pragmática.

\section{Attribution of mental states and conversational awareness: a study with preschool students}

\begin{abstract}
The ability to attribute to oneself and to someone else mental states as desires, intentions and beliefs, has been called theory of mind. Recent studies show links between aspects of language and acquisition of theory of mind. This study investigates the relationship between conversational awareness, seen as an aspect of the pragmatic of language, and the attribution of mental states. Twenty eight children from 4 to 6 years old, both genders and low socioeconomic level participated in it. For the assessment of conversational awareness and theory of mind, tasks from the literature were used. The results showed the effects of age in favor of older children for the two variables and a positive correlation between them. These results are discussed based on other studies in the literature.
\end{abstract}

Keywords: theory of mind, preschool students, pragmatic.

\section{Atribución de estados mentales y comprensión conversacional: estudio con preescolares}

\begin{abstract}
Resumen: La habilidad de atribuir a si mismo y al otro estados mentales como deseos, intenciones e creencias ha sido denominada teoría de la mente. Investigaciones recientes muestran relaciones entre aspectos del lenguaje y la adquisición de la teoría de la mente. Este estudio investiga las relaciones entre la comprensión conversacional, vista como uno de los aspectos del lenguaje, y la atribución de estados mentales. Participaron 28 niños de 4 a 6 años, de los dos sexos y bajo nivel socioeconómico. Para la evaluación de la comprensión conversacional y la teoría de la mente fueron aplicadas individualmente tareas existentes en la literatura. Los resultados mostraron efecto de la edad a favor de los niños mayores para las dos variables, bien como una correlación positiva entre ellas. Esos resultados son discutidos considerándose otras investigaciones en la literatura.
\end{abstract}

Palabras clave: teoría de la mente, preescolares, pragmática.

Grande parte dos estudos que enfocam o desenvolvimento da compreensão da mente do outro são encontrados na literatura psicológica sob a designação de teoria da mente, significando o entendimento que as crianças elaboram, durante os primeiros anos de vida, a respeito da mente, ou seja, a respeito das emoções, intenções, pensamentos e crenças das pessoas com que se deparam em seu cotidiano. Explicar como se

\footnotetext{
${ }^{1}$ Colaboraram neste estudo os pós-graduandos Ivani de Oliveira Magalhães Santos, Adriana Soares de Freitas Souza e Lina Maria de Moraes Carvalho. ${ }^{2}$ Endereço para correspondência:

Maria Regina Maluf. R. Dr. Renato Paes de Barros, 227, apto 12.

CEP 04.530-000, São Paulo-SP, Brasil. E-mail: marmaluf@gmail.com.
}

desenvolve na criança a compreensão da mente do outro é um empreendimento da maior importância, tanto para psicólogos quanto para educadores, dadas as implicações e aplicações desse conhecimento nas mais diversas atividades voltadas para o favorecimento do desenvolvimento social e da aprendizagem escolar durante os primeiros anos de vida.

Foi no final da década de 70 e início dos anos 80 que se multiplicaram os estudos de psicologia cognitiva que se propunham a conhecer o lado mental do comportamento, tanto em seres humanos quanto em animais (Amsel, 1989). David Premack e Guy Woodruff realizavam pesquisas sobre cognição animal e em 1978 publicaram os resultados de um experimento onde pela primeira vez utilizaram o termo teoria 
da mente (Premack \& Woodruff, 1978). A nova proposta de procedimento metodológico foi acolhida com entusiasmo por muitos pesquisadores que passaram a investigar o surgimento, nas crianças, da capacidade de compreensão da mente do outro. Essas pesquisas consolidaram-se no âmbito da tradição experimental com o paradigma da crença falsa, desenvolvido por Wimmer e Perner (1983). Desde então vêm se multiplicando as pesquisas voltadas para o estudo da cognição social, sob a forma de atribuição de estados mentais ao outro, e mais especificamente, de atribuição de crença falsa.

A pesquisa de comportamentos de atribuição de estados mentais aos outros é uma forma de aproximação do complexo processo de cognição social que se instala durante os primeiros anos de vida das crianças. Como mostra Goswami (2008), a cognição social diz respeito a comportamentos que permitem inferir que o indivíduo imputa estados mentais - desejos, intenções e crenças - para si mesmo e para os outros. A observação desses comportamentos leva a supor que eles resultam de um sistema de inferências que pode ser visto como uma "teoria" uma vez que os estados mentais não são diretamente observáveis. Esse sistema de inferências pode ser utilizado para predizer o comportamento de outros (Astington \& Baird, 1995; Bosa \& Callias, 2000).

Uma revisão das pesquisas brasileiras sobre teoria da mente (Valério, Panciera, Domingues, \& Maluf, 2007) permitiu verificar que o estudo mais antigo foi publicado em 1993 (Dias, 1993), portanto dez anos após a publicação do artigo de Wimmer e Perner (1983). Foram encontrados 17 artigos de periódicos (seis análises teóricas e onze pesquisas empíricas), onze dissertações de mestrado e quatro teses de doutorado. A análise mostrou que esses trabalhos pesquisaram a habilidade das crianças para predizer ações baseadas em crenças e desejos de outras pessoas, o uso e compreensão de verbos mentais, os efeitos da idade, do contexto sociocultural e da linguagem sobre o desenvolvimento da teoria da mente.

$\mathrm{Na}$ educação infantil, as experiências de conversação são vistas como tendo um papel importante para favorecer o desenvolvimento das crianças. As práticas linguísticas que envolvem conversação implicam a compreensão e uso das regras e convenções que governam a utilização da linguagem nos diferentes meios sociais, ou seja, a pragmática da linguagem. Essa dimensão da linguagem parece ter papel significativo no desenvolvimento da teoria da mente e tem sido avaliada empiricamente por meio do desempenho de crianças em tarefas designadas como sendo de avaliação da compreensão conversacional (Deleau, Guehenneuc, Le Sourn, \& Ricard, 1999; Deleau, Maluf, \& Panciera, 2008).

O termo compreensão conversacional designa a compreensão que o indivíduo tem a respeito do "funcionamento" das conversações, ou seja, do caráter normativo (ou contra-normativo) desse tipo de comportamento social. Essa compreensão se elabora nos primeiros anos de vida, juntamente com a aquisição da linguagem oral. Conforme argumenta Siegal (1999), a conversação pode ser vista como um dos domínios do conhecimento, aceitando-se que a comunicação efetiva entre falantes e ouvintes envolve uma plataforma comum de conhecimentos sobre tempo, localização e associações que permite a representação mental mútua de contextos para a compreensão. Nesse sentido pode-se supor que as inferências conversacionais interferem no desempenho das crianças em tarefas cognitivas que exigem linguagem.

As pesquisas mais recentes que tratam do desenvolvimento da teoria da mente e da linguagem, buscam ir além de uma medida global do desenvolvimento da linguagem e se voltam para algumas de suas dimensões específicas (Souza, 2006). Uma dessas dimensões reside no aspecto pragmático do funcionamento da linguagem. Admite-se que, nas conversações diárias, a criança compartilha e revê crenças comuns e assim tem a experiência da possibilidade de alterar crenças dos outros e ajustar as suas próprias crenças (Deleau, Maluf, \& Panciera, 2008).

Na literatura brasileira a expressão compreensão conversacional vem sendo utilizada como tradução da expressão inglesa conversational awareness (Siegal, 1999), que em francês corresponde a clairvoyance conversationnelle (Deleau, 1999). Na presente pesquisa, compreensão conversacional designa os conhecimentos implícitos relativos à pragmática da linguagem, que estão presentes nas situações de conversação. Significa uma habilidade social relacionada ao aspecto pragmático da linguagem e pode ser avaliada por meio de tarefas que envolvem situações de conversação.

Algumas dessas tarefas de avaliação da compreensão conversacional, operacionalizadas por Deleau e Guehenneuc (1999), foram traduzidas e adaptadas para serem aplicadas a crianças brasileiras (Panciera, 2002; Valério, 2003). Elas possibilitam verificar a compreensão que a criança tem das regras e convenções implícitas na conversação, de acordo com sua cultura. São utilizadas imagens de cenas familiares, a partir das quais o aplicador mantém interação linguística com a criança, sob a forma de perguntas e respostas. Assim por exemplo, frente a um desenho de um adulto falando com uma criança e outro em que há uma criança falando com um adulto, o aplicador relata para a criança que alguém disse: "se você comprar balinhas para mim eu vou ficar super contente..." E pergunta: "quem está dizendo isso e para quem está dizendo"? Espera-se que a criança que tem a pragmática da linguagem mais desenvolvida compreenda que, nesta nossa cultura, uma criança pede ao adulto que lhe compre balas mas o contrário não é verdadeiro.

Pesquisas anteriores (Deleau, 1999; Deleau, Guehenneuc, Le Sourn, \& Ricard, 1999) investigaram como e em que momento do desenvolvimento a criança desenvolve a compreensão conversacional, isto é, adquire competência para compreender e utilizar as regras sociais que regem a comunicação em seu meio cultural. Estudos realizados com crianças brasileiras (Panciera, 2002; Panciera, Valério, Maluf, \& Deleau, 2008; Valério, 2003) deram sustentação à hipótese de que a compreensão que as crianças mostram a respeito das conversações se desenvolve com a idade e parece estar relacionada com a teoria da mente.

O estudo de Panciera (2002) foi realizado com 60 crianças, de quatro a seis anos, provenientes de famílias de baixa renda e 
que frequentavam uma instituição educacional filantrópica. Teve como objetivo avaliar a compreensão conversacional e suas relações com a atribuição de crença falsa ao outro. Para a avaliação da compreensão conversacional foram utilizadas as mesmas quatro tarefas do estudo de Deleau e cols. (1999), traduzidas e adaptadas para o português do Brasil. Essas tarefas visam os quatro domínios da pragmática da linguagem, a saber: relacionar um ato de linguagem ao papel social do outro, identificar qual dos interlocutores pode compreender a mensagem do locutor, reconhecer e retificar um falso enunciado em situação de conversação, compreender as regras de ajustamento da informação. Para avaliação da habilidade de atribuição de crença falsa ao outro foi utilizada a tarefa de Sally e Ann, desenvolvida por Baron-Cohen, Leslie e Frith (1985). Os resultados confirmaram o caráter desenvolvimental da compreensão conversacional, mostrando um salto qualitativo nesta habilidade quando foram comparadas as crianças entre quatro e cinco anos. Entre as de cinco e seis anos de idade havia uma diferença, porém não era estatisticamente significativa, o que permitiu sustentar a hipótese de que o período mais importante para o desenvolvimento dessa habilidade situase entre os quatro e cinco anos. Por outro lado, a compreensão conversacional mostrou-se significativamente correlacionada com a habilidade de atribuição de crença falsa.

No estudo de Valério (2003) o instrumento de avaliação da compreensão conversacional foi aprimorado, substituindo-se as imagens utilizadas para aplicação das quatro tarefas por imagens equivalentes retiradas de personagens da Turma da Mônica desenhados por Maurício de Souza (Souza, 1998). Para avaliação da habilidade de atribuição de crença falsa foi utilizada a mesma tarefa de Sally e Ann. A pesquisa teve como objetivo avaliar a compreensão conversacional e suas relações com a capacidade de atribuição de crença falsa, em crianças de nível socioeconômico médio-alto, que frequentavam uma instituição de ensino da rede particular, reconhecida por desenvolver um programa de educação infantil com projeto pedagógico consolidado. Participaram 60 crianças de quatro a seis anos. Os resultados mostraram que as crianças de quatro anos obtiveram pontuações significativamente mais baixas do que as crianças de cinco anos nas provas de compreensão conversacional. Mas não houve diferença estatisticamente significativa entre as crianças de cinco e seis anos. Foi possível concluir que nesse grupo de crianças a compreensão conversacional se desenvolveu sobretudo no período de quatro a cinco anos. Na tarefa de crença falsa não foi possível discriminar o efeito da idade, uma vez que todas as crianças, à exceção de uma, deram a resposta correta na prova, levando os pesquisadores a admitir efeito teto na aplicação da tarefa. Quando comparados aos resultados obtidos por Panciera (2002), estes achados mostram que as crianças deste estudo (Valério, 2003) obtiveram melhores resultados nas tarefas de compreensão conversacional e na tarefa de atribuição de crença falsa. Esses melhores resultados foram entendidos como efeito favorável do contexto sociocultural e educacional, uma vez que estas crianças, diferentemente daquelas do estudo anterior, frequentam uma escola com projeto pedagógico e são provenientes de famílias mais escolarizadas.
Essas duas pesquisas utilizaram somente uma tarefa para avaliação da habilidade de atribuição de crença falsa, o que dificultou a verificação das associações entre compreensão conversacional, entendida como um aspecto da pragmática da linguagem e teoria da mente, entendida como atribuição de estados mentais. Os resultados foram considerados preliminares e as autoras recomendaram novos estudos, com a utilização de mais de uma tarefa de atribuição de crença falsa.

Estes resultados inspiraram a realização da presente pesquisa, que teve como participantes crianças de nível socioeconômico baixo, que frequentavam uma creche e foram escolhidas pelo critério idade, mantendo-se uma diferença de 12 meses entre os dois grupos de idade investigados. Foram utilizados os mesmos instrumentos das pesquisas anteriores, com as seguintes variações: ao invés de quatro tarefas de avaliação da compreensão conversacional foram utilizadas as duas que em pesquisas anteriores mostraram maior poder de discriminação; ao invés de uma tarefa de avaliação da habilidade de atribuição de estados mentais foram utilizadas quatro tarefas da escala de tarefas em teoria da mente, conforme proposta por Wellman e Liu (2004), com o objetivo de garantir uma avaliação mais completa.

São objetivos da pesquisa: (a) verificar como se apresentam a compreensão conversacional e a atribuição de crença falsa em crianças de duas faixas etárias que frequentam uma escola de educação infantil e as possíveis diferenças entre elas; (b) analisar as relações entre a habilidade de compreensão conversacional e a atribuição de crença falsa.

\section{Método}

\section{Participantes}

A pesquisa foi realizada em um Centro de Educação Infantil que atende crianças de diferentes idades, provenientes de famílias de baixa renda. Participaram 28 crianças de quatro a seis anos, distribuídas em dois grupos de idade com diferença de 12 meses entre eles: Grupo 1: 14 crianças, de 48 a 52 meses (média de idade $=49,2$ meses), sendo seis meninas e oito meninos; Grupo 2: 14 crianças, de 65 a 73 meses (média de idade = 67,7 meses), sendo cinco meninas e nove meninos.

\section{Considerações éticas}

Quanto aos cuidados éticos, o projeto recebeu aprovação do Comitê de Ética em Pesquisa da Pontifícia Universidade Católica de São Paulo. Obteve-se o consentimento livre e esclarecido dos responsáveis pelas crianças e também se tomou o cuidado de manter o anonimato das crianças e da creche.

\section{Instrumentos e procedimento de coleta de dados}

Para avaliação da compreensão conversacional foram utilizadas tarefas do instrumento de Deleau e Guehenneuc (1999), 
conforme adaptadas para o português por Panciera (2002) e Valério (2003). Para avaliação da teoria da mente foram aplicadas quatro tarefas retiradas da escala de tarefas de Wellman e Liu (2004), tal como traduzidas por Panciera (2007).

Todas as aplicações foram individuais e realizadas na creche em que as crianças eram atendidas. As tarefas foram aplicadas em duas sessões: uma para as tarefas de compreensão conversacional e uma para as tarefas de teoria da mente, alternando-se a ordem de aplicação.

\section{Avaliação da compreensão conversacional}

Dentre as quatro tarefas de avaliação da compreensão conversacional foram escolhidas as tarefas 2 e 4 . A escolha foi baseada em estudos anteriores que as consideraram como tendo maior potencial de avaliação (Bernard \& Deleau, 2007; Panciera, 2007).

A tarefa 2 avalia em que medida a criança compreende que, para se referir a um dado acontecimento, a formulação verbal difere se o interlocutor já sabe sobre o que se fala, ou se ele não sabe ainda. Em outras palavras, avalia o aspecto da pragmática da linguagem que consiste na capacidade de reconhecer a adequação de um referente em função do conhecimento prévio que o enunciador tem do seu interlocutor.

Tarefa 2: A tarefa consiste em 12 pranchas, havendo em cada uma delas quatro quadros que dão sequência a uma história. Nos três primeiros quadros, dois ou três personagens estão ocupados, fazendo alguma coisa. No quarto quadro há um balão associado a um personagem (o enunciador), além de mais dois ou três personagens, sendo que um ou dois deles já estavam presentes nos quadros anteriores e um ou dois deles são novos. A tarefa da criança consiste em dizer a que personagem o enunciador dirige a mensagem, ou seja, se a dirige ao que acabou de chegar ou àquele(s) que já estava(m) presente(s) na situação apresentada na história.

A resposta é considerada correta e recebe 1 ponto se a criança compreende a que interlocutor o enunciado é endereçado de fato.

A tarefa 4 verifica a sensibilidade dos participantes à violação das máximas conversacionais descritas por Grice (1975) como regras de conversação. Os enunciados infringem uma das máximas de Grice: de quantidade (falar não mais nem menos do que foi solicitado), qualidade (tentar falar a verdade e evitar mentiras), pertinência (ser relevante e informativo) ou modo (evitar obscuridade e ambiguidade). Solicita-se que a criança faça o julgamento sobre duas respostas dadas a uma mesma questão, sendo que uma delas viola regras da conversação e a outra não.

Tarefa 4: É composta por dez itens. Em cada um deles o aplicador relata para a criança uma situação de conversação entre três personagens: Dona Ursa e dois ursinhos, Maneco e Tuca, todos confeccionados com papel colorido e colados em palitos de madeira. Em cada item, Dona Ursa coloca uma questão e os ursinhos, que "nem sempre escutam bem" ou "não prestam muita atenção", às vezes dão respostas "tolas". A criança deverá identificar, entre duas respostas, a de Maneco e a de Tuca, qual foi a resposta "tolinha", ou seja, a que não foi a melhor resposta, porque não seguiu as máximas da conversação.

A resposta correta, que recebe 1 ponto, é a que reconhece quando essas regras implícitas da conversação não foram seguidas.

\section{Avaliação da teoria da mente}

Para a avaliação da teoria da mente foram utilizadas tarefas de atribuição de estados mentais de crença e de crença falsa. Optou-se pelas tarefas 2, 3, 4 e 5 da escala de 7 tarefas de Wellman e Liu (2004), traduzidas por Panciera (2007). A tarefa 1 não foi aplicada por ter sido considerada muito fácil para esse grupo de crianças.

A tarefa 2 avalia se a criança se mostra capaz de reconhecer que o outro pode ter uma crença diferente da sua.

Tarefa 2: O material consistiu em uma boneca de brinquedo e uma folha de papel com os desenhos de uma árvore e de uma garagem. Todo o material fica visível à criança. A boneca é apresentada à criança e o aplicador diz: - Aqui está Aninha. Aninha quer encontrar o gato dela. O gato pode estar escondido na garagem ou ele pode estar escondido em cima da árvore. O aplicador mostra a folha de papel com os desenhos da árvore e da garagem. - Onde você acha que o gato dela está? Na garagem ou em cima da árvore? Espera-se que a criança dê uma das duas respostas. $\mathrm{O}$ aplicador escolhe a resposta diferente da que a criança deu e continua:Bom, essa é uma boa idéia, mas a Aninha pensa que o gato está na garagem/árvore. Ela acha que o gato dela está na garagem/árvore (apresentando a resposta alternativa àquela dada pela criança). - Agora Aninha vai procurar o gato dela. Onde Aninha vai procurar primeiro o gato dela? Na árvore ou na garagem?

A resposta correta, que recebe 1 ponto, é de que Aninha vai procurar primeiro o gato ali onde ela acha que ele está (mesmo que na realidade ele não esteja lá).

A tarefa 3 verifica se a criança é capaz de perceber se o outro teve ou não acesso à fonte de informação.

Tarefa 3: O material utilizado consiste em uma caixa e um cachorro de plástico, que permanecem visíveis à criança, e uma boneca, não visível à criança. O aplicador diz: - Aqui está uma caixa. O que você acha que 
tem dentro dessa caixa? A criança pode dar qualquer resposta. Em seguida, a caixa é aberta e mostra-se a ela o conteúdo. - Vamos ver... tem um cachorrinho dentro! O aplicador fecha a caixa, e diz: - Certo, o que tem dentro da caixa? (aguarda-se a resposta da criança). Após a resposta, a bonequinha de brinquedo é apresentada: - Esta é Carol. - Carol nunca (com ênfase) olhou dentro dessa caixa. Então, Carol sabe o que tem dentro da caixa? (aguarda-se a resposta da criança) $\mathrm{O}$ aplicador pergunta novamente: - Carol olhou dentro dessa caixa? (aguarda-se a resposta da criança).

A resposta correta, que recebe 1 ponto, é de que Carol não sabe o que tem dentro da caixa (ela nunca olhou dentro da caixa).

A tarefa 4 avalia se a criança é capaz de atribuir crença falsa ao personagem da história.

Tarefa 4: O material consiste em uma caixa de band-aid vazia e um peixinho de plástico, que permanecem visíveis à criança; e um boneco, que não está visível. - Aqui está uma caixa de band-aid. O que você acha que tem dentro desta caixa? (aguarda-se a resposta da criança). Em seguida, a caixa é aberta e mostra-se à criança o conteúdo: - Vamos ver... tem um peixinho dentro! O aplicador fecha a caixa: - Certo, o que tem dentro da caixa de band-aid? (aguarda-se a resposta da criança). Então, um boneco é apresentado: - Este é Pedrinho. Pedrinho nunca (com ênfase) olhou dentro dessa caixa de band-aid. Então, o que o Pedrinho "pensa" que tem dentro da caixa? Band-aid ou um peixinho? (aguarda-se a resposta da criança). O experimentador indaga: - Por quê? (aguarda-se a resposta da criança). - Pedrinho olhou dentro dessa caixa? (aguarda-se a resposta da criança).

A resposta correta, que recebe 1 ponto, é de que Pedrinho "pensa" que tem band-aid na caixa (Pedrinho não olhou dentro da caixa).

A tarefa 5 verifica a crença falsa, de modo mais explícito.

Tarefa 5: O material consiste em um boneco e uma folha de papel com os desenhos de uma mochila e um armário. Todo o material fica visível à criança. Nessa tarefa o boneco é apresentado à criança e o aplicador relata: - Aqui está Dudu. Dudu quer achar a canetinha dele. A canetinha pode estar na mochila ou pode estar no armário. - De verdade, a canetinha do Dudu está na mochila. Mas Dudu "acha" que a canetinha está no armário. Então, qual o primeiro lugar que Dudu vai procurar a canetinha dele? Na mochila ou no armário? (aguarda-se a resposta da criança). O aplicador mostra a folha de papel com os desenhos da mochila e do armário e pergunta: - Por que? (aguarda a resposta da criança). - Onde a canetinha do Dudu está de verdade? Na mochila ou no armário? (aguarda-se a resposta da criança).

A resposta correta, que recebe 1 ponto, é de que Dudu irá procurar a canetinha dentro do armário, porque ele "acha" que ela está lá.

\section{Análise dos dados}

Para cada item das tarefas de compreensão conversacional foi atribuído 1 (um) ponto para resposta correta e 0 (zero) para resposta incorreta. A tarefa 2 tem 12 itens e a tarefa 4 tem 10 itens.

Nas avaliações de crença falsa, para cada tarefa foi atribuído 1 (um) ponto para a resposta correta e 0 (zero) para a resposta incorreta.

\section{Resultados}

Foram analisados os resultados obtidos quanto à habilidade de compreensão conversacional, vista como um aspecto da pragmática da linguagem e a habilidade de compreensão social manifestada na resolução de tarefas de teoria da mente.

Quanto à compreensão conversacional, como se pode ver na Tabela 1 as crianças mais velhas (Grupo 2) obtiveram escores superiores aos das crianças mais novas (Grupo 1) nas duas tarefas, conforme era esperado.

Tabela 1

Resultados das duas tarefas de compreensão conversacional obtidos pelas 14 crianças do G1 e 14 crianças do G2, considerando-se escore e porcentagem de acertos na Tarefa 2 e na Tarefa 4

\begin{tabular}{|c|c|c|c|c|c|c|}
\hline \multirow{3}{*}{ Grupos } & \multirow{3}{*}{$\begin{array}{l}\text { Média } \\
\text { de idade }\end{array}$} & \multirow{3}{*}{$\mathbf{N}=$} & \multicolumn{4}{|c|}{ Tarefas de Compreensão Conversacional } \\
\hline & & & \multicolumn{2}{|c|}{ T2 } & \multicolumn{2}{|c|}{ T4 } \\
\hline & & & Acertos & $\%$ & Acertos & $\%$ \\
\hline G1 & 49,2 & 14 & 84 & 50 & 76 & 54,28 \\
\hline G2 & 67,7 & 14 & 112 & 66,66 & 83 & 59,28 \\
\hline
\end{tabular}

T2: 12 itens; escore máximo para o grupo $=168$

T4: 10 itens; escore máximo para o grupo $=140$

Na habilidade de compreender que quando alguém se dirige a um interlocutor, deve fazê-lo de modo diferente se ele conhece ou não o conteúdo da mensagem (Tarefa 2), a soma dos acertos nos 12 itens foi de $112(66,66 \%)$ para as crianças mais velhas (G2), contra 84 acertos (50\%) das mais novas (G1).

A aplicação do teste $t$ de Student mostrou que a diferença é estatisticamente significativa a favor das crianças mais velhas $(t=-3,272 ; p=0,001)$.

A Figura 1 permite comparar visualmente os resultados das crianças de quatro e de cimco anos, com vantagens para estas últimas. 


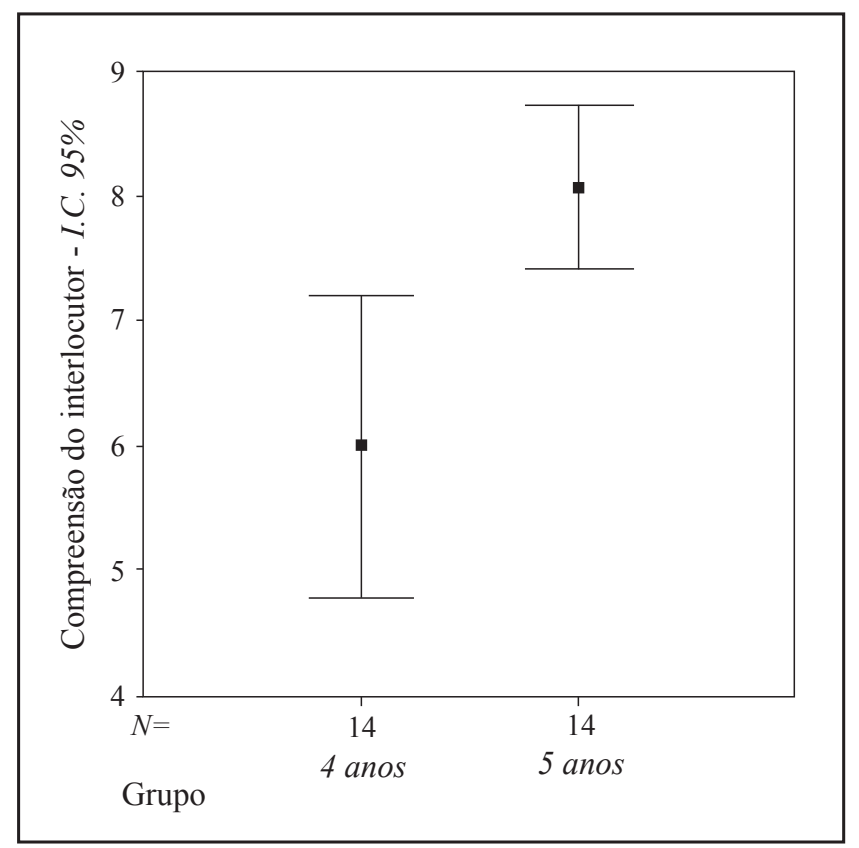

Figura 1. Resultados das crianças de 4 anos (G1) e de 5 anos (G2) na tarefa 2 de compreensão conversacional, que avalia a habilidade de dirigir-se ao interlocutor apropriado.

$\mathrm{Na}$ tarefa 4, que verifica se a criança compreende violações das regras de conversação, a soma dos acertos nos 10 itens foi de $83(59,28 \%)$ para as mais velhas (G2), contra 76 acertos $(54,28 \%)$ das mais novas. Esse é o aspecto da pragmática da linguagem que diz respeito à compreensão da pertinência assertiva nas conversações. As crianças de cinco anos obtiveram número maior de acertos, porém a diferença em relação às de quatro anos não se mostrou significativa $(t=$ $-0,710 ; p=0,24)$.

A Figura 2 permite visualizar os resultados melhores, embora não significativos, das crianças de cinco anos quando comparadas às de quatro anos.

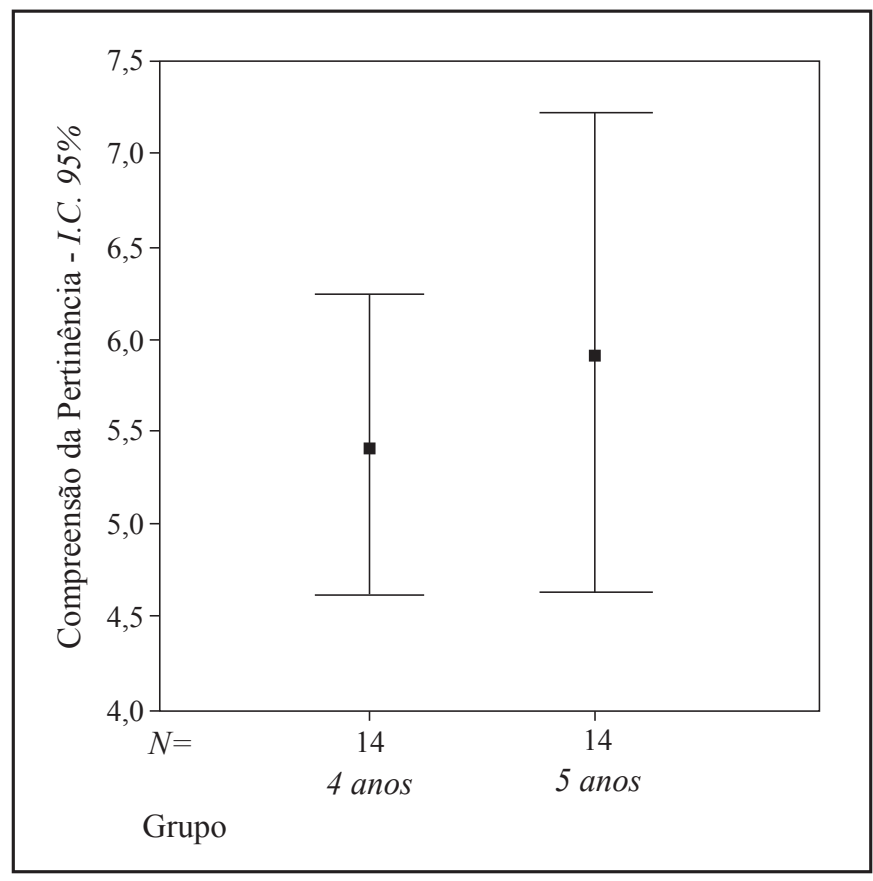

Figura 2. Resultados das crianças de 4 anos (G1) e de 5 anos (G2) na tarefa 4 de compreensão conversacional, que avalia a compreensão da pertinência assertiva nas conversações. 
Pode-se concluir que se sustenta a hipótese do efeito da idade na manifestação da habilidade de compreensão conversacional, que claramente progride entre os quatro e cinco anos de idade.

No que diz respeito à atribuição de estados mentais ao outro, vista como uma forma de compreensão social e verificada por meio da solução de tarefas de teoria da mente retiradas da escala desenvolvida por Wellman e Liu (2004), os resultados obtidos mostram igualmente um forte efeito da idade, conforme se pode ver na Tabela 2 .

Tabela 2

Resultados das quatro tarefas de teoria da mente, obtidos pelas 14 crianças do G1 e 14 crianças do G2, considerando-se escore e porcentagem de acertos em cada tarefa

\begin{tabular}{|c|c|c|c|c|c|c|c|c|c|c|}
\hline \multirow{3}{*}{ Grupos } & \multirow{3}{*}{ Média de idade } & \multirow{3}{*}{$\mathbf{N}=$} & \multicolumn{8}{|c|}{ Tarefas de Teoria da Mente } \\
\hline & & & \multicolumn{2}{|c|}{$\mathbf{T 2}$} & \multicolumn{2}{|c|}{ T3 } & \multicolumn{2}{|c|}{ T4 } & \multicolumn{2}{|c|}{ T5 } \\
\hline & & & Acertos & $\%$ & Acertos & $\%$ & Acertos & $\%$ & Acertos & $\%$ \\
\hline G2 & 67,7 & 14 & 10 & 71,43 & 10 & 71,43 & 7 & 50,00 & 8 & 57,14 \\
\hline
\end{tabular}

Cada tarefa tem uma possibilidade de acerto; o escore máximo para cada grupo é igual a 14.

Nas quatro tarefas de teoria da mente os escores das crianças do G2, que são as mais velhas, é mais alto do que o das crianças mais novas do G1. Se considerarmos a soma das quatro tarefas, teremos um total de 35 acertos para as crianças de cinco anos (G2), contra um total de somente 21 acertos para as crianças de quatro anos (G1).
A aplicação do teste $t$ de Student mostrou que a diferença é estatisticamente significativa a favor das crianças mais velhas $(t=-2,28 ; p=0,01)$. Essa diferença pode ser visualizada na Figura 3 , onde fica bastante evidente a tendência a maior compreensão das tarefas de teoria da mente pelas crianças de cinco anos.

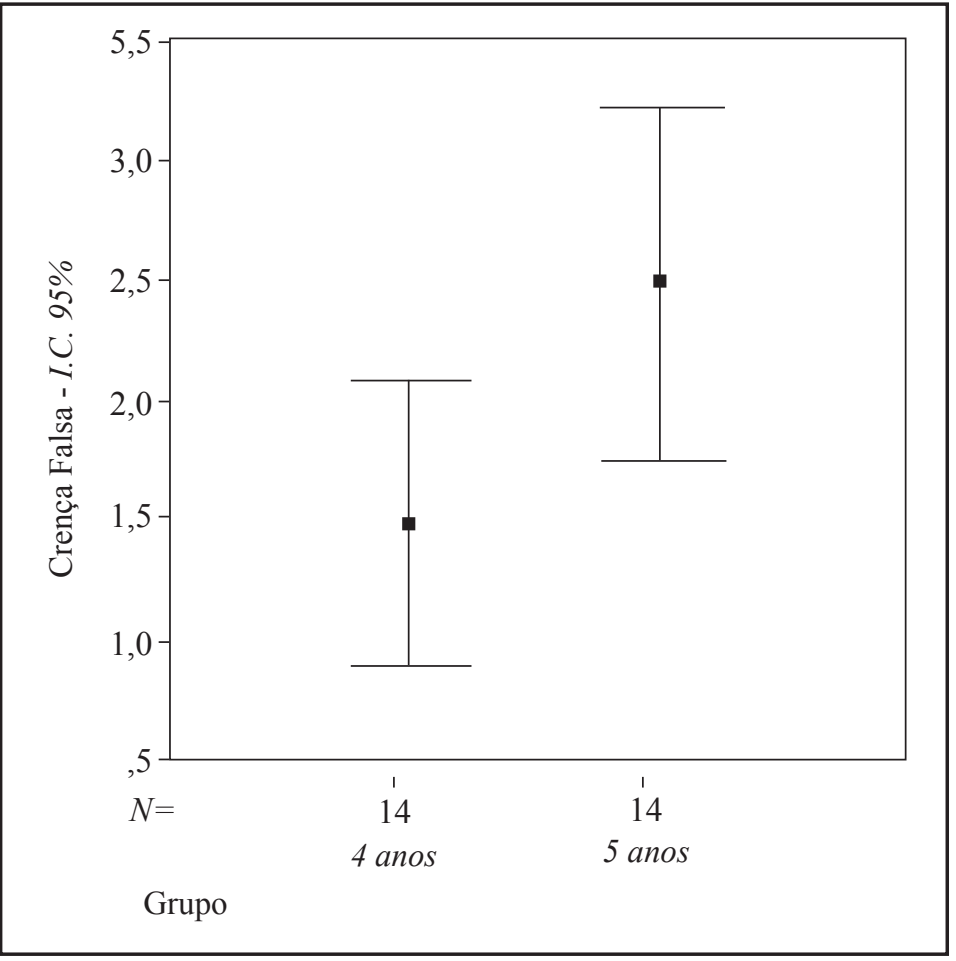

Figura 3. Resultados das crianças de 4 anos (G1) e de 5 anos (G2) nas quatro tarefas de teoria da mente. 
Para responder à questão de uma possível relação entre as habilidades de compreensão conversacional e de teoria da mente foram confrontados os resultados das 28 crianças nas tarefas 2 e 4 de compreensão conversacional com os resultados obtidos nas quatro tarefas de atribuição de estados mentais, utilizandose o teste de correlação de Pearson. Obteve-se como resultado uma correlação de $0,433, \operatorname{com} p=0,011$, o que permite sustentar a hipótese de associação entre essas duas habilidades.

Esses resultados apontam para um efeito da idade na habilidade das crianças para compreender as regras da conversação, bem como para a compreensão de estados mentais na resolução de tarefas de teoria da mente.

\section{Discussão}

Os resultados obtidos permitem afirmar que as crianças das duas faixas etárias estudadas se diferenciam em alguns aspectos da pragmática da linguagem e nas tarefas de teoria da mente, com melhores resultados para as crianças mais velhas, o que está de acordo com resultados anteriores nesse campo de pesquisa sobre desenvolvimento na etapa da educação infantil.

$\mathrm{O}$ aspecto da pragmática da linguagem em que a diferença se mostrou significativa é o reconhecimento da adequação da mensagem ao interlocutor (Tarefa 2, $p=0,001$ ). Para o reconhecimento da pertinência assertiva nas conversações, a diferença entre os dois grupos de idade não foi significativa (Tarefa $4, p=0,24$ ).

Estes resultados estão de acordo com outros encontrados na literatura, que sugerem que essa dimensão da pragmática, que consiste na habilidade de compreensão da pertinência assertiva nas conversações, tende a ser instalada mais tarde, uma vez que parece apresentar maiores dificuldades de compreensão (Hogrefe, Wimmer, \& Perner, 1986). Foi verificado também que para as crianças de cinco anos a tarefa 2 de compreensão conversacional parece ser mais fácil do que a tarefa 4 ( $\mathrm{T} 2=66,66 \%$; T4 $=59,28 \%$ ), conforme já havia sido verificado anteriormente (Deleau e cols., 1999). No entanto, essa mesma relação não ocorreu para as crianças mais novas (T2 = 50\%; T4 $=54,28 \%$ ), que obtiveram maior número de acertos na habilidade de pragmática da linguagem avaliada na tarefa 4. Novos estudos, com maior número de participantes, são necessários para avançar nesse aspecto da questão.

A correlação encontrada entre compreensão conversacional e a habilidade de atribuição de crenças está de acordo com resultados anteriores (Deleau e cols., 1999), dando sustentação à nossa hipótese inicial. No entanto, essa associação entre a pragmática da linguagem e a teoria da mente deve ser objeto de análises ulteriores, que possam explorar os diferentes aspectos da dimensão pragmática da linguagem, além dos explorados na presente pesquisa.

O exame dos resultados dos dois grupos de crianças de diferentes idades, para cada uma das tarefas de teoria da mente, levou à conclusão de que não se percebe uma sequência totalmente ascendente ou descendente nos escores, ou seja: existe certa diminuição nos acertos das crianças mais novas, da tarefa 2 para a tarefa 4 da escala de tarefas de teoria da mente (sobre um escore máximo de 14, acertaram 7, 5, 4, 5); nas crianças mais velhas há um número razoavelmente alto de acertos nas duas primeiras tarefas e depois certa diminuição (sobre um escore máximo de 14, acertaram 10, 10, 7, 8). Novos estudos, com maior número de participantes são fortemente recomendados para avaliar o valor discriminatório dessas tarefas para crianças brasileiras, uma vez que o número pequeno de participantes não permite conclusões vigorosas sobre a consistência da escala. Por outra parte, os resultados obtidos levam a rever a decisão de não aplicar a tarefa 1 da escala por considerá-la "muito fácil" para essas crianças, uma vez que nenhuma delas crianças atingiu o teto de acertos nas outras tarefas consideradas mais difíceis.

\section{Considerações finais}

No Brasil verifica-se um crescente interesse por pesquisas na área das relações entre atribuição de estados mentais e linguagem. Os achados da presente pesquisa estão de acordo com resultados anteriores (Maluf, Deleau, Panciera, Valério, \& Domingues 2004; Panciera 2002, 2007; Valério, 2003) obtidos com crianças pré-escolares falantes do português. Tais resultados sugerem a necessidade de novos estudos que explorem não somente os aspectos da pragmática da linguagem, mas também outras dimensões da linguagem, como a sintática e a semântica (Deleau e cols., 2008).

Pesquisas anteriores mostraram as influências decorrentes do contexto sociocultural e das condições educacionais (Maluf, Deleau, Panciera, Valério, \& Domingues, 2004; Panciera, 2002, 2007; Panciera, Valério, Maluf, \& Deleau, 2008; Valério, 2003) no desenvolvimento das habilidades de compreensão conversacional e de atribuição de estados mentais. Estudos de intervenção visando facilitar o desenvolvimento de habilidades de atribuição de estados mentais e a compreensão da crença falsa, mostraram que a estimulação linguística tem um efeito positivo sobre o desenvolvimento da teoria da mente em crianças pré-escolares (Domingues, 2006; Domingues \& Maluf, 2008; Oliveira, 2009; Panciera, 2007; Souza, 2009). Essa estimulação deve ser favorecida tanto na escola quanto nas famílias. Estudos longitudinais também podem dar importante contribuição à pesquisa das relações entre aspectos da linguagem e teoria da mente. Valério (2008) mostrou que atribuições precoces de estados mentais de emoção podem ser encontradas aos dois anos e cinco meses e que atribuições de crença surgiram aos três anos e dois meses. Estas são questões com grande potencial teórico e prático, com implicações na educação infantil, tanto no que concerne às práticas escolares quanto familiares, que poderão ser estudadas em pesquisas ulteriores.

\section{Referências}

Amsel,A.(1989). Behaviorism, neobehaviorism and cognitivism in learning theory. New Jersey: Lawrence Erlbaum. 
Astington, J. W., \& Baird, J. A. (1995). Introduction: Why language matters. In J. W. Astington \& J. A. Baird (Eds.), Why language matters for theory of mind (pp. 3-25). Oxford, NY: Oxford University Press.

Baron-Cohen, S., Leslie, A. M., \& Frith, U. (1985). Does the autistic child have a 'theory of mind'? Cognition, 21, 37-46.

Bernard, S., \& Deleau, M. (2007). Conversational perspectivetaking and false believe attribution: A longitudinal study. British Journal of Developmental Psychology, 25, 443460.

Bosa, C. A., \& Callias, M. (2000). Autismo: Breve revisão de diferentes abordagens. Psicologia: Reflexão e Crítica, 13, $167-177$.

Deleau, M. (1999). Assessing links between conversational awareness and cognitive development. Developmental Science, 2(1), 16-18.

Deleau, M., \& Guehenneuc, K. (1999). La clairvoyance conversationelle chez l’enfant d’âge pré-scolaire. Un essai d'opéraionnalisation et ses premiers résultats. Journée d'Étude sur le Développement Conceptuel et Langagier de l'Enfant de 1 à 6 ans. Besançon, France.

Deleau, M., Guehenneuc, K., Le Sourn, S., \& Ricard, M. (1999). Clairvoyance conversationnelle et théorie de 1'esprit. Enfance, 3, 238-247.

Deleau, M., Maluf, M. R., \& Panciera, S. D. P. (2008). O papel da linguagem no desenvolvimento de uma teoria da mente: Como e quando as crianças se tornam capazes de representações de estados mentais. In T. M. Sperb \& M. R. Maluf (Orgs), Desenvolvimento sociocognitivo: Estudos brasileiros sobre a teoria da mente (pp. 191-247). São Paulo: Vetor.

Dias, M. G. B. B. (1993). O desenvolvimento do conhecimento da criança sobre a mente. Psicologia: Teoria e Pesquisa, 9, 587-600.

Domingues, S. F. S. (2006). Teoria da mente: Um procedimento de intervenção aplicado em crianças de 3 a 4 anos. Tese de doutorado não publicada, Pontifícia Universidade Católica de São Paulo, São Paulo.

Domingues, S. F. S., \& Maluf, M. R. (2008). Compreendendo estados mentais: Procedimentos de pesquisa a partir da tarefa original de crença falsa. In T. M. Sperb \& M. R. Maluf (Orgs.), Desenvolvimento sociocognitivo: Estudos brasileiros sobre teoria da mente (pp. 11-31). São Paulo: Vetor.

Goswami, U. (2008). Cognitive development: The learning brain. New York: Psychology Press.

Grice, H. P. (1975). Logic and conversation. In P. Cole \& J. L. Morgan (Eds), Syntax and semantics, 3: Speech acts (pp. 41-58). New York: Cambridge University Press.

Hogrefe, G., Wimmer, H., \& Perner, J. (1986). Ignorance versus false belief: A developmental lag in attribution of epistemic states. Child Development, 57, 567-586.
Maluf, M. R., Deleau, M., Panciera, S. D. P., Valério, A., \& Domingues, S. F. S. (2004). A teoria da mente: Mais um passo na compreensão da mente das crianças. In M. R. Maluf (Org.), Psicologia educacional: Questões contemporâneas (pp. 53-88). São Paulo: Casa do Psicólogo.

Oliveira, F. G. (2009). Práticas discursivas maternas e compreensão de estados mentais: Um estudo com crianças de 3 anos a 6 meses a 4 anos. Tese de doutorado não publicada, Pontifícia Universidade Católica de São Paulo, São Paulo, SP.

Panciera, S. D. P. (2002). Compreensão conversacional $e$ atribuição de estados mentais: Um estudo com préescolares de 4 a 6 anos. Dissertação de mestrado não publicada, Pontifícia Universidade Católica de São Paulo, São Paulo, SP.

Panciera, S. D. P. (2007). Linguagem e desenvolvimento da teoria da mente: Um estudo com crianças de 3 a 5 anos. Tese de doutorado não publicada, Universidade de São Paulo, São Paulo.

Panciera, S. D. P., Valério, A., Maluf, M. R., \& Deleau, M. (2008). Pragmática da linguagem e desenvolvimento da teoria da mente: estudos com pré-escolares. In T. M. Sperb \& M. R. Maluf (Orgs.), Desenvolvimento sociocognitivo: Estudos brasileiros sobre a teoria da mente (pp. 191-247). São Paulo: Vetor.

Premack, D., \& Woodruff, G. (1978). Does the chimpanzee have a theory of mind? Behavioral and Brain Science, 1, 515-526.

Siegal, M. (1999). Language and thought: The fundamental significance of conversational awareness for cognitive development. Developmental Science, 2, 1-14.

Souza, A. S. F. (2009). Teoria da mente e desenvolvimento infantil: Um procedimento de intervenção com crianças no interior da Bahia. Dissertação de mestrado não publicada, Pontifícia Universidade Católica de São Paulo, São Paulo.

Souza, D. H. (2006). Falando sobre a mente: Algumas considerações sobre a relação entre linguagem e teoria da mente. Psicologia: Reflexão e Crítica, 19, 387-394.

Souza, M. (1998). Quadrinhos da Turma da Mônica [CDROM]. São Paulo: FTD.

Valério, A. (2003). Compreensão conversacional: Um estudo realizado com crianças de 4 a 6 anos. Dissertação de mestrado não publicada, Pontifícia Universidade Católica de São Paulo, São Paulo.

Valério, A. (2008). A constituição da teoria da mente: Estudo longitudinal sobre uso de termos mentais em situação lúdica e desempenho em tarefas de crença e crença falsa. Tese de doutorado não publicada, Pontifícia Universidade Católica de São Paulo, São Paulo.

Valério, A., Panciera, S. D. P., Domingues, S. F. S., \& Maluf, M. R. (2007). As pesquisas brasileiras sobre teoria da mente: Uma revisão de literatura [Resumo]. Anais do Congresso Nacional de Psicologia Escolar e Educacional, 8. 
Wellman, H. M., \& Liu, D. (2004). Scaling of theory of mind tasks. Child Development, 75, 523-541.

Wimmer, H., \& Perner, J. (1983). Beliefs about beliefs: Representation and constraining function of wrong beliefs in young children's understanding of deception. Cognition, 13,103-128.

Maria Regina Maluf é Professora Titular do Programa de Estudos Pós-graduados em Educação da Pontifícia Universidade Católica de São Paulo.

Elianna Cristina Gallo-Penna é doutoranda no Programa de Estudos Pós-graduados em Educação da Pontifícia Universidade Católica de São Paulo, bolsista da CAPES.

Maria José dos Santos é professora do curso de Pedagogia, campus Catalão da Universidade Federal de Goiás.

Recebido: 27/04/2009

$1^{a}$ revisão: $10 / 12 / 2009$

$2^{a}$ revisão: $13 / 10 / 2010$

Aceite final: 16/12/2010 